\title{
Pieces of a Thousand Stories: Repatriation of the History of Aboriginal Sydney
}

\author{
Peter Read \\ University of Sydney \\ Suzana Sukovic \\ University of Sydney
}

\begin{abstract}
The on-line project A History of Aboriginal Sydney ${ }^{1}$, based at the University of Sydney, takes existing educational and Australian Indigenous digital initiatives in a new direction. By dividing Sydney into six geographical areas, we are creating a knowledge base of post-invasion Aboriginal history, incorporating different forms of tagging, timeline and digital mapping to provide multiple paths to information in text, videos, still images and, in the future, three dimensional reconstructions of former living areas. After eighteen months research we are maintaining a balance between unearthing new and forgotten material, incorporating it into our developing database, and exploring the potential of digital mapping, animation and 3D historical reconstruction for educational and research purposes. With close Indigenous consultation, especially the Aboriginal Educational Consultative Groups, we hope to digitally construct the Aboriginal history of Sydney and return it to the people who have been deprived of so much of their history for so long.
\end{abstract}

\section{Introduction}

A lost history? While Sydney Aboriginal families still carry their own oral histories, very often they are much fragmented. Laws and cruel or thoughtless bureaucratic action closed off much information that was the right of every young person to know. Government policies accidentally or deliberately put an end to their historical knowledge by separating old from young, families from children, grandparents from parents, knowledge holders from knowledge receivers, and by breaking up community living areas. Stolen Generations children grew up knowing nothing. Some families thought it best, from the mid-nineteenth century, not to identify as Aboriginal at all. Indeed, some families have only recently discovered their descent from historic Aboriginal individuals in the last two decades. Partly because so much was lost, family histories are now frequently and fiercely contested by others, who may deny a clan association to their opponents or even the Indigenous identity itself.

\footnotetext{
1 The website will be accessible from December 2010 at www.historyofaboriginalsydney.edu.au
} 
A huge amount of bureaucratic history is still locked up in the state archives, of great importance to historians as well as communities: but thanks to the exercise of somewhat arbitrary privacy laws, they are almost totally closed. Despite the closures and restrictions, some specialist historians of Aboriginal Australia have made some remarkable advances. A few scraps of information are available in local histories, generally in the introductions, before the writer gets on to the 'main' (read 'non Aboriginal') story. Works by Sydney Aboriginal people themselves are few, though short oral histories are beginning to fill out the gaps. Research by specialist historians of Aboriginal Australia has uncovered a remarkable amount of information, but while some of their works remain well known, many are out of print, and some excellent doctoral theses unknown or, for community members, are difficult to access. So what remains is piecemeal, and often disputed. Such is the disagreement on clan, tribal and linguistic boundaries today, that it would be probably impossible now to draw up a definitive linguistic map of the Sydney region as it was in 1788.

\section{Background: Indigenous visitors and migrants}

Nor did things stay the same after 1788. It is held by an Aboriginal oral tradition that people from the south coast, keeping Governor Phillip’s flotilla in sight, were able to keep pace by walking parallel to the ships and so the first visitors from outside, as well as those living in what became known as Sydney, were there to greet the fleet as they dropped anchor in Botany Bay. Aboriginal immigration had begun.

Within eighteen months a smallpox epidemic had killed perhaps ninety per cent of the Harbourside population. Clanspeople probably already having customary rights in Sydney began to occupy the spaces: north of the harbour a young man, Bungaree, from the north side of Broken Bay, came to settle from time to time near Kirribilli. Today it is his language group, known today as Guringai, that has given its name to the Sydney Municipal Council Ku-Ring-Gai. At the same time, Aboriginal visitors and travellers from south west and the south continued to visit traditional areas like today’s La Perouse.

Migrations to Sydney continued, interrupted by periodic clearing of communities from around the harbour. Sydney was the focus of radical Aboriginal action in the nineteen 
twenties and 'thirties'. ${ }^{2}$ After the Second World War, thousands of people, especially from northern New South Wales, were beginning an economic migration to Redfern and surrounding suburbs. Traditional camping grounds continued to be destroyed by local councils and the residents transferred to western Sydney. By the 1970s many hundreds of Aboriginal people were moving from eastern to western Sydney by force, or under the promise of a Housing Commission house.

The nineteen eighties and nineties were a time of re-recognising clan and language differences, obscured in some cases for a century. The 1983 New South Wales Land Rights Act established the right to join a Local Land Council to anyone of Indigenous descent, which sometimes drove an acrimonious wedge between 'traditional owners' (those who could trace their descent to people once living in the area covered by the Land Council) and anyone whose ancestors had arrived some time after the First Fleet. Family loyalties strengthened here, weakened there. Those who for decades had regarded themselves as undifferentiated 'Blackfellas' became much more aware of their heritage as members of the old Sydney clans like Gai-mariagal (Camaraigal), Darug or Gandangara, and often of even more precisely located geographical regions. Today’s Aboriginal population is huge, vibrant, energetic and feisty.

There is still much complex historical knowledge to be both unearthed and much to be repatriated back into the Indigenous communities of Sydney. But what materials should be included in this contested mix - and how? The urban area of Sydney holds about some ten per cent of all the Aboriginal people in Australia drawn from every part of the country (ABS, 2007). Any project trying to return the lost history to the Sydney communities and simultaneously to educate students in a vital part of the nation's history, will need to explain how many different peoples came to be living here, the diversity of their cultures, movement patterns, changing attitudes, legislation, and relations with the outside society and between the people themselves. Representing this contemporary and historical complexity is the challenge for our team of historians, researchers, film makers, web developers and educators working together on A History of Aboriginal Sydney. ${ }^{3}$

\footnotetext{
${ }^{2}$ Radical action included the foundation of the Aboriginal Progressive Association, a Petition to the King, an Aboriginal newspaper Abo Call and, in 1938, a National Day of Mourning.

${ }^{3}$ We wish to acknowledge contributions of core members of our team: Julie Janson, Senior Research Officer, Sheena Kitchener, Film Maker and Video Editor and Andrey Inkin, Web Developer.
} 


\section{Digital repatriation and learning}

A public awareness of Aboriginal issues and the significance of support for different cultures have been raised in both Indigenous and non-Indigenous communities in recent decades. Aboriginal elders, teachers and community workers have all stressed the importance of educating young Aboriginal people about their history and traditions. Teaching of Australian Indigenous studies at all levels of education has been strongly recommended in numerous government documents over the last two decades (Gunstone 2008).

The New South Wales Department of Education requires that Aboriginal Studies be taught for a semester in Year 9, directing students to specific topics like 'women and children' and 'Stolen Generations'. While developed with best intentions, it is often unclear what resources are available to teachers. Often lacking expertise themselves, teachers draw upon on-line material like reports of government enquiries (Commission 1997), study kits (Reconciliation 1991-2000) or Aboriginal-controlled genealogical and personal material from the central desert (Ara Irititja Project 2007, TKRP 2010), which may leave students knowing something about Queensland and the Central Desert, and very little about Sydney. The few resources about Aboriginal Sydney such as Barani (Sydney City Council 2002) are not sufficient to support formal teaching and community interest in learning about Sydney’s past. Aboriginal students will have even less history of individual Sydney people - their own forebears - or events in individual suburbs. We want our project to be, simultaneously, Sydney wide, but also specifically local; to follow the national leaders as well as the family heads, government policies and the exact sites where they were evolved and had their consequences.

\section{Digital platform}

From the onset of the project we considered a publicly available website to be the most appropriate way of delivering information to teachers, students and communities. Computers and the Internet are available in homes, schools and libraries. Unlike most remote areas, Sydney has reliable Internet connection and, as pointed out by Holloway (2005), somewhat higher computer and Internet usage than the rest of Australia as a whole. Data from Census 2006 show that nearly 51 per cent of Sydney households where Indigenous persons lived, had Internet connection compared with 66 per cent of other households (ABS 2008). 
Socio-economic disadvantage, on the other hand, is likely to limit benefits of online resources. Numerous studies showed that the Internet adoption coincides with higher socioeconomic status (for example, Porter and Donthu 2006, Willis and Tranter 2006, Goldfarb and Prince 2008). The income may be also related to certain patterns of usage. Low-income Americans, for example, spend significant number of hours on online entertainment, but they are less likely to use the Internet for e-commerce and research (Goldfarb and Prince 2008). In his analysis of results of Australian Census 2001, Holloway (2005) noticed that a lower computer and Internet usage in the west and south west of Sydney is closely aligned with areas of socio-economic disadvantage. Similarly to Internet users elsewhere (Chinn and Fairlie, 2007, Orviska and Hudson, 2009), Internet users in Sydney are predominantly younger, non-Indigenous people who tend to be highly educated and with higher income (Holloway 2005).

While socio-economic disadvantage of a significant part of Indigenous population and a lower level of Internet access at home are likely to limit the use of online sources in Aboriginal communities, it could be expected that older generations would be affected more than younger people, especially students, who use the Internet regularly as part of their school work and social life. Indigenous people in Sydney who are younger, enrolled in educational programs, and have higher socio-economic status are likely to use the Internet for research and, generally, in the same way as other comparable groups. Teachers are also likely to use the Internet regularly for their work. Despite obstacles in physical and intellectual access to online sources, the Internet is still widely accessible to the majority of Sydneysiders and it is particularly appropriate for students and teachers who are our main audience.

Digital delivery provides some unique advantages, not least that it is the most appropriate for our data, which has been gathered mainly in digital forms. Images, videos, copies of archival materials are all gathered and kept in digital formats, so digital delivery avoids problems associated with the loss of quality or problems in transferring data. For students and teachers, digital formats provide a desired flexibility for downloading and their own use of materials. Many families maintain their digital collections of images and documents, which could be extended by copies of materials from our website and families may decide to contribute their digital materials to the project.

Finally, all data on the website is the result of academic research, which should be preserved and archived for future use. Aboriginal and Torre Strait Islanders’ Data Archive (ATSIDA) 
hosts the project by providing space for the website and archival solutions for long-term use of research data. The current project interface is designed so it can change and grow to reflect the project development and future needs of communities and researchers without affecting the fundamental aspect of the project - to collect and repatriate pieces of stories about Aboriginal history in Sydney. Ethical protocols devised by the University of Sydney and the Jumbunna House of Aboriginal Learning (University of Technology, Sydney) ensure that participants hold the initial and continuing right of determining access to their material.

\section{Reconstruction begins}

Uncovering Aboriginal history in the middle of a modern urban place where everyone seems to be consumed by busy daily lives, requires refocusing on barely visible traces around us. Looking for dispersed fragments, scraping surfaces to discover lost tracks and documenting the significance of seemingly ordinary things are our approaches to the recovery of lost paths. As we will explain below, the research team has collected and arranged pieces, but site visitors will have to construct their own track.

We want to create a space where Sydneysiders of Aboriginal descent can look at their history and consider their sense of origin, and where non-Indigenous people can look at a history in which main events are not battles with neighbouring countries or coronations of faraway rulers. A quick look at our timeline will show that deliveries of blankets interwoven with numerous acts of forced humiliation form a principal thread of this marginalised history. At the same time, we want to show traditional Indigenous plants, objects and rituals thriving in modern suburban backyards. To do that, we draw upon Indigenous knowledge and traditions as well as Western research practices, archives and technology.

Our work is ethnographic in the sense that it is descriptive and interpretative. We are aware that ' $[t]$ he ethnographer, assuming the role of broker, should make all efforts to ensure the participation of indigenous people in as much planning and implementation as possible.' (Purcell and Onjoro, 2002, p. 178). We have consulted very widely both among traditional owners of north coastal Sydney and later arrivals. However, we are aware that all our efforts to ensure full Indigenous consultation are similar to our efforts to provide exhaustive, reliable and appropriate historical material. As Indigenous people do not represent a unified community, our advisers represent a range of Aboriginal community voices, not all of them. In the end, there are always views which remain unrepresented. With all its flexibility and 
openness, the project is presented as one particular construction of pieces. We do not deny that our selection of voices is necessarily subjective and guided by our interpretation. Our research material, however, will be available via ATSIDA, again under appropriate protocols, to anyone else who wants to develop their own interpretation.

How did we construct this digital space? Considering the significance of land in Indigenous cultures, an acute sense of lost places and the locality in everyday life, we chose place and people as key organising principles of the knowledge base and the website. The website is organised around six main localities: North Coastal, Central, South Coastal, South West, West and North West.

Visual representations are of particular importance in Indigenous traditions and, at the same time, they are essential for digital media. Simple visual elements such as a change of colour are used throughout the site as a navigational element so all pages associated with one place are marked by the same colour. The project logo (Figure 1) is a modern interpretation of traditional Aboriginal symbols for place and movement.

While being acceptable and easy to use for everyone, we wanted our site, first of all, to 'talk' to young people and support their exploration of the past and uncovering of their sense of belonging and identity. Jessica Birk, an artist and a young Koori woman, has been our guide in developing an appearance, which would suit the sensibility of young Indigenous people in Sydney. Birk designed the project logo and advised us on the site visual design. The sometimes gloomy text of the past unfolds against a black backdrop highlighted with lively colours, which we see as a representation of a new spirit of energy and hope.

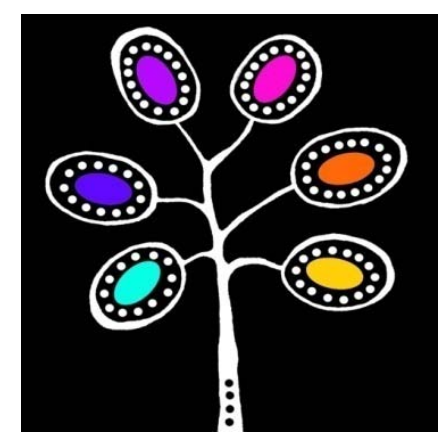

Figure 1. Logo, designed by Jessica Birk

Discovering \& contextualising 
Material is structured in a way that aids navigation and encourages visitors to make their own discoveries and interpretations. By using a system of tagging text and images, an interactive timeline and map as well as free text searching, we provide different ways of accessing information and seeing it in different contexts.

For example, information about Marramarra Creek could be encountered and retrieved in many different ways depending on users' needs and interests. It appears in a chronological description of events where text from a historical source is related to a contemporary picture of the place (Figures 2 and 3).

We have developed a way of tagging text, which enables retrieval of all textual passages on the particular topic. Tag 'Sites: Historic', for example, will retrieve all references to Marramarra Creek in the text (Figure 4). Tags have been developed to reflect teaching topics and aid students' work with the materials, but they are also chosen as suitable descriptors.

\section{6}

The government of NSW forms a Select Committee to look into conditions of Aborigines. Rev William West Simpson, the Anglican Minister at the Lower Hawkesbury (Wiseman's Ferry) sends the following note:

In Marramarra Creek I have found a family of half castes, the children of John Lewis or Ferdinand, a white man employed in the lime burning trade... The motherisBiddy, the sister of the blackfellow Bowen, of Pitt Water and the daughter of an aboriginal woman by an English seaman. There are seven children by this connexion, from nineteen to two years of age, living in their father's house after the manner of the settlers of the Creek... The two lads are employed in the boat with their father, four of the younger children are yet at home, and the eldest girl is living with a man of the name of Rose, a fisherman at Marramarra Creek. (NSW Legislative Council Select Committee 1846 , quoted by Richmond)

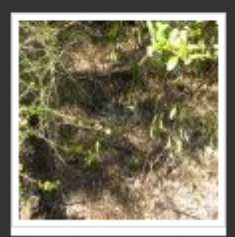

Birth of twins John and James to Elizabeth and Israel Rose at Marramarra Creek. (Richmond 2003, P. 3)

NSW Legisla tive Council Select Committee takes evidence from Reverend John McKenny: "The numbers (of Aboriginal people) were greatly diminished ... about 5 years ago by an epidemic said to be measles which carried off a great many". There are many reported cases of white men living with Aboriginal women and having children. (NSW Legislative Council Select Committee 1846)

\section{Figure 2. Page describing events at Marramarra Creek}




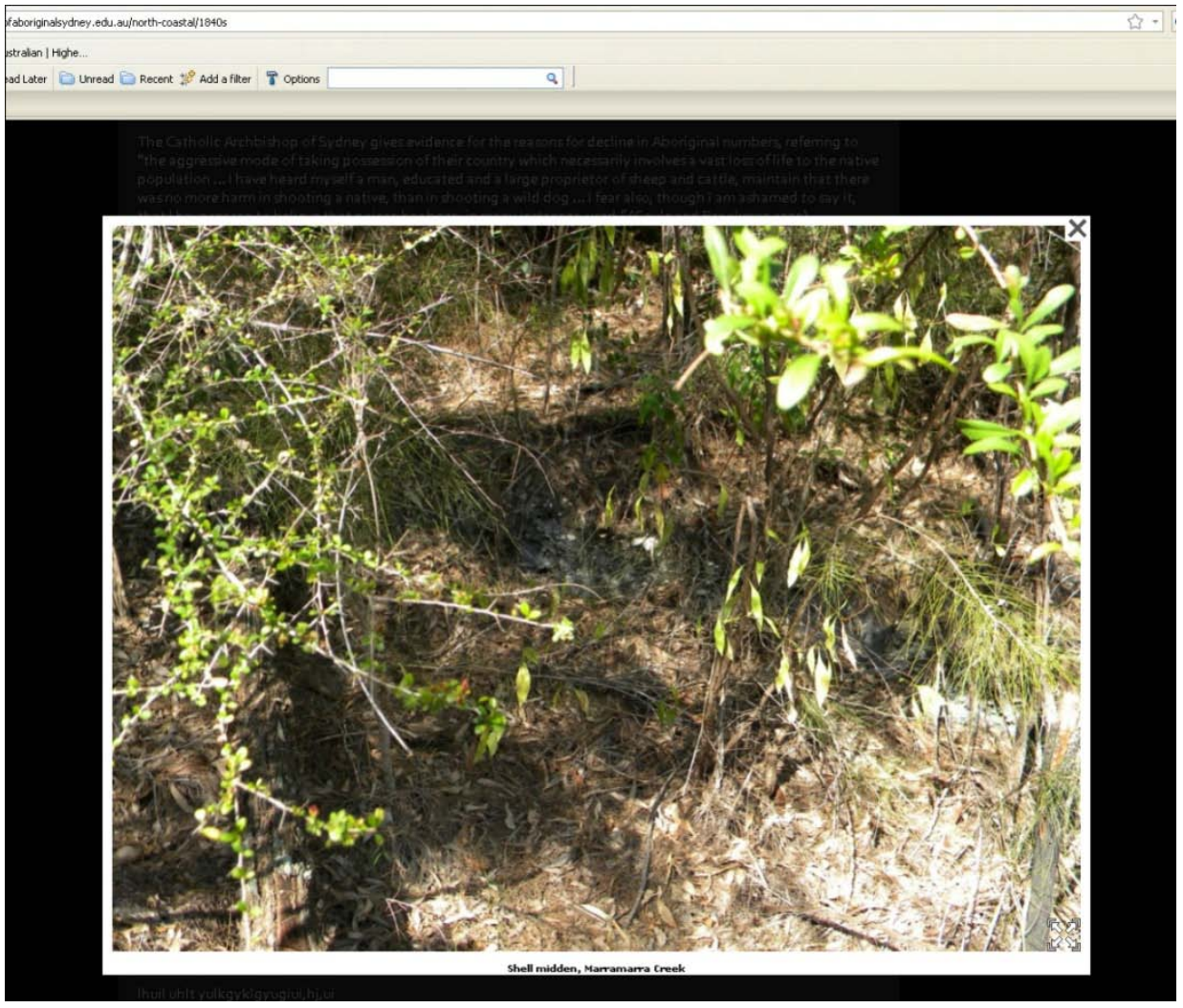

Figure 3. Picture from the contemporary site: Shell midden, Marramarra Creek

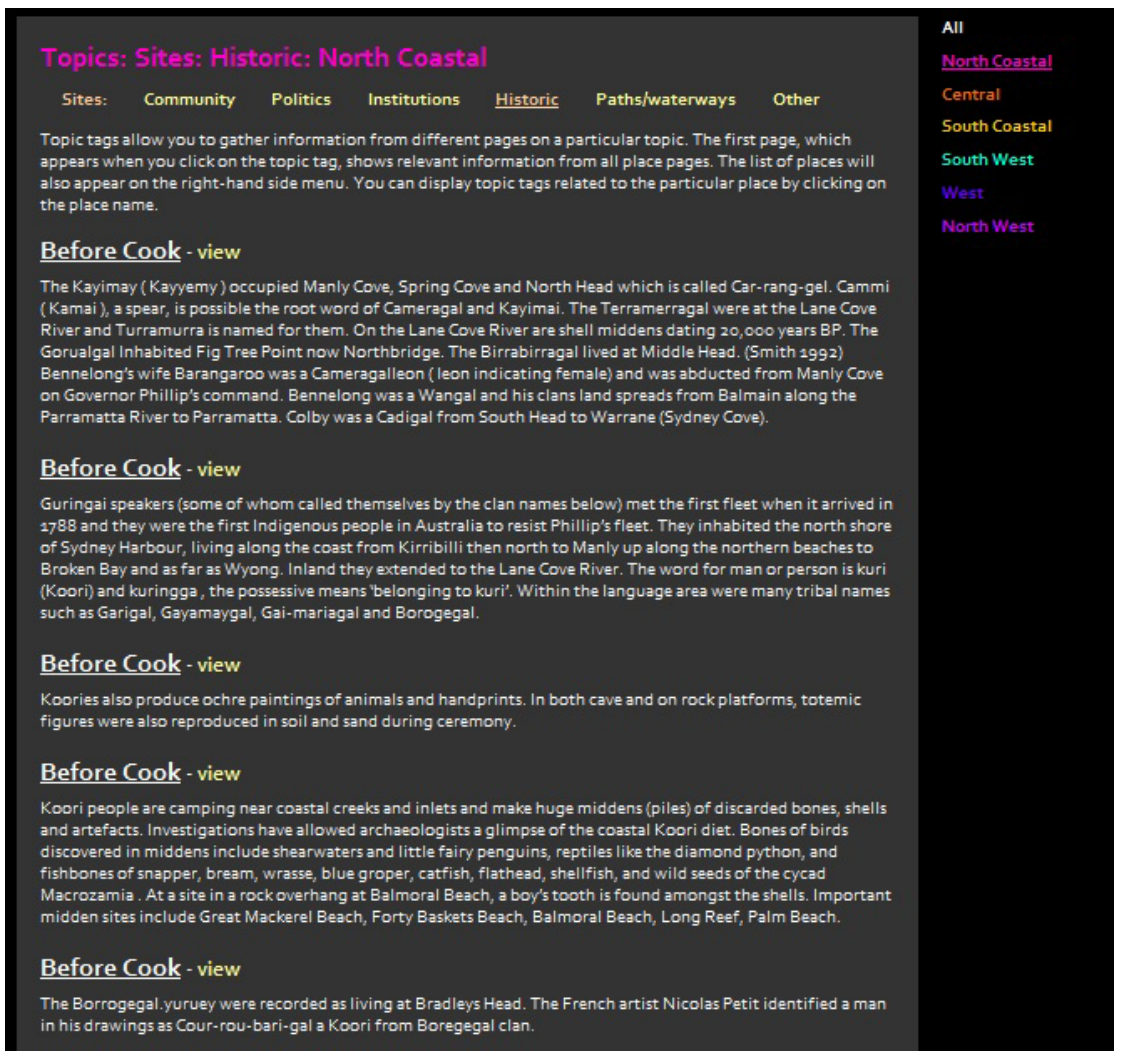

Figure 4. Text retrieval by tag name 
Images and videos appear in the relevant gallery and can be viewed with other sources related to the place (Figure 5) or a particular tag. Free text search by word 'Marramarra' will also reveal all text passages and resources labelled with this word so the user can see all pictures and, in the future, videos related to the place as well as all textual information related to Marramarra Creek.

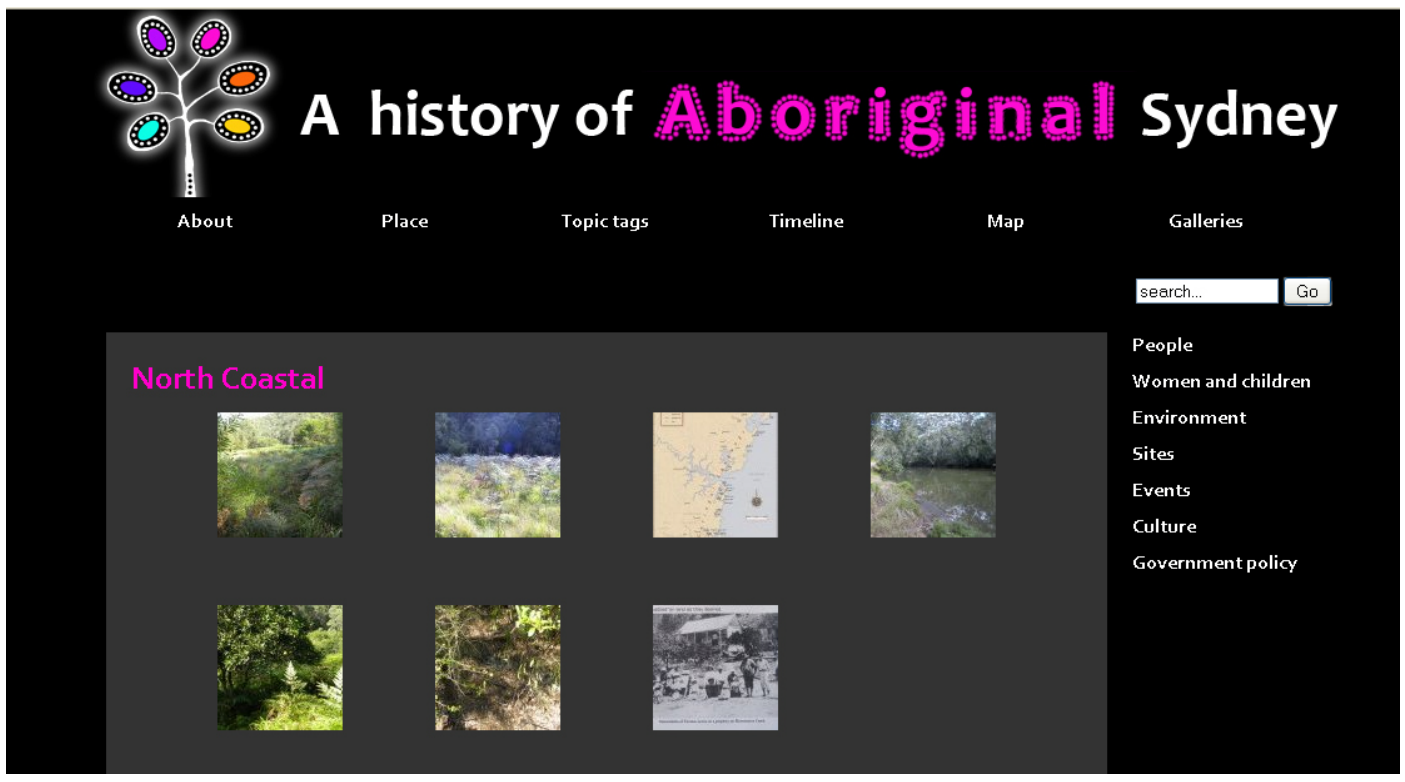

Figure 5. Image gallery - North Coastal

The interactive timeline shows events chronologically. In the example below, events at Marramarra Creek in 1846 could be seen plotted on the interactive timeline, where events are outlined briefly and additional information appears by clicking on a hyperlink (Figure 6).

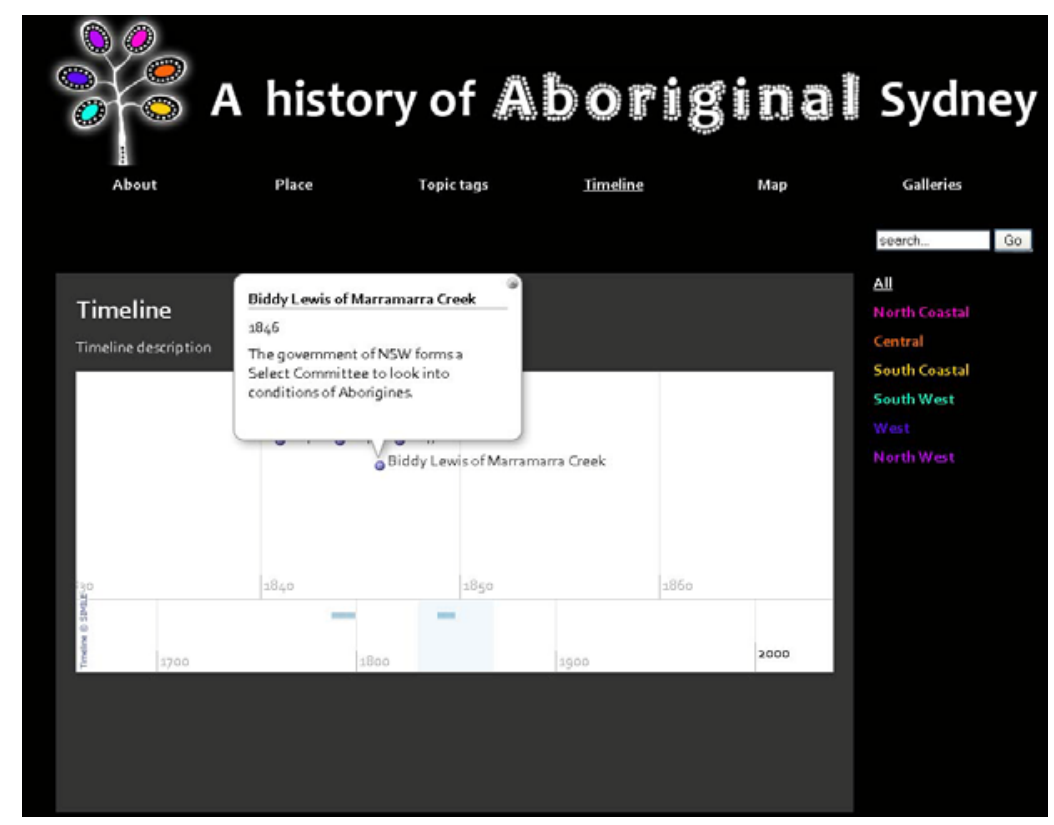

Figure 6. Timeline 
Marramarra Creek can be also seen on the interactive map (Figure 7). We are recording interviews with Aboriginal elders at certain localities telling their stories and explaining the significance of the place.

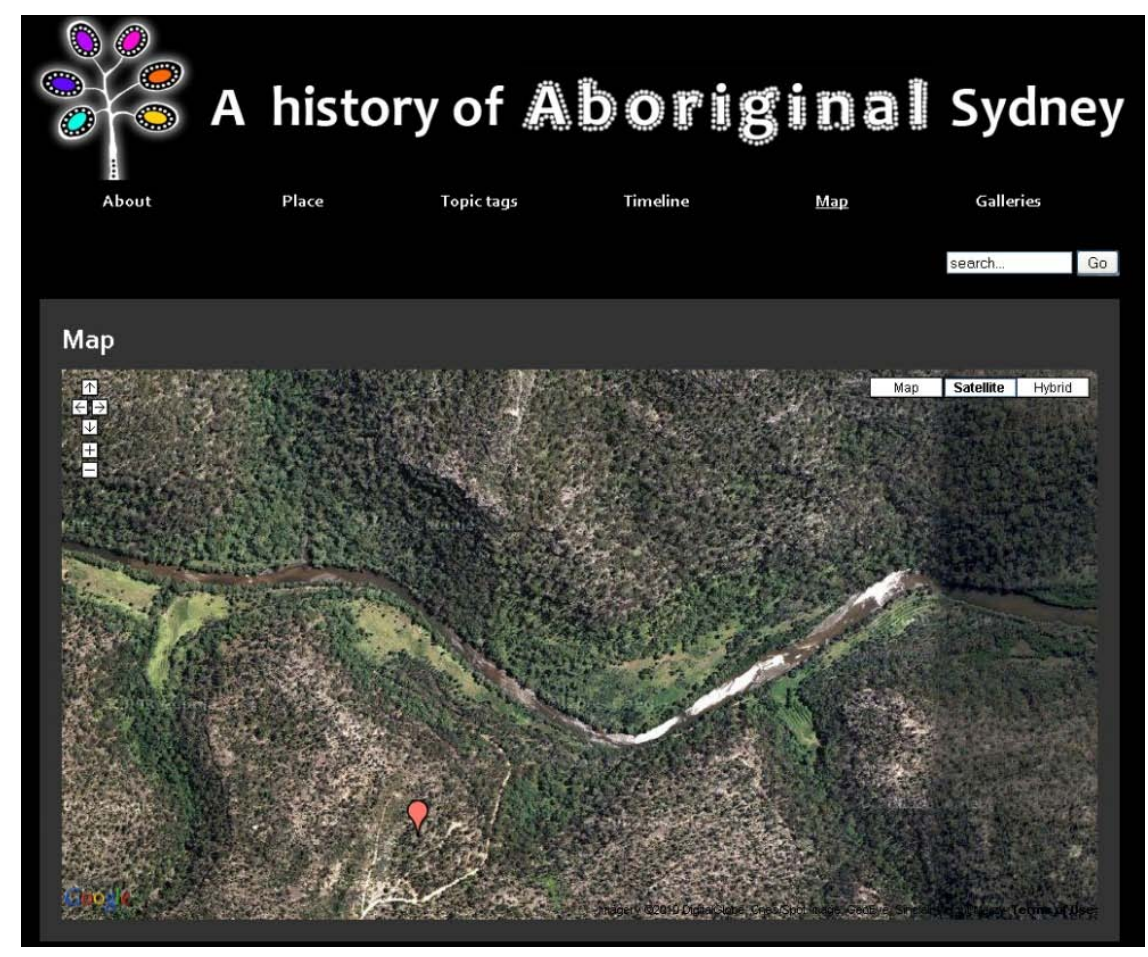

Figure 7. Interactive map

As the user browses the site, information appears in glimpses that can be viewed and enjoyed as small pieces of a puzzle, or explored and followed further. Archival material in this environment is energised by appearing in alluring glimpses, disappearing, only to reveal different meanings in new contexts. Monk wrote about displays of old photographs: 'What was once a photographic window on their world was now only a museum vitrine where all subjective individuality vanished in the generality of an ethnographic display’ (Monk and Tan, 2007, Tuesday, February 6, 2007, para. 4). Digital displays provide opportunities to tease imagination, which lends subjectivity to exhibits in digital vitrine. As Monk notes elsewhere in the same book, '...each generation often skips to its grandparents' era to be struck by photography's disturbance, that is, by photography's difference for them... Consensus on photography's disturbance coincidentally reappears at moments of technological change, along the fault lines of its disruptions...' (Monk and Tan, 2007, Friday, September 15, 2006, para. 6). 


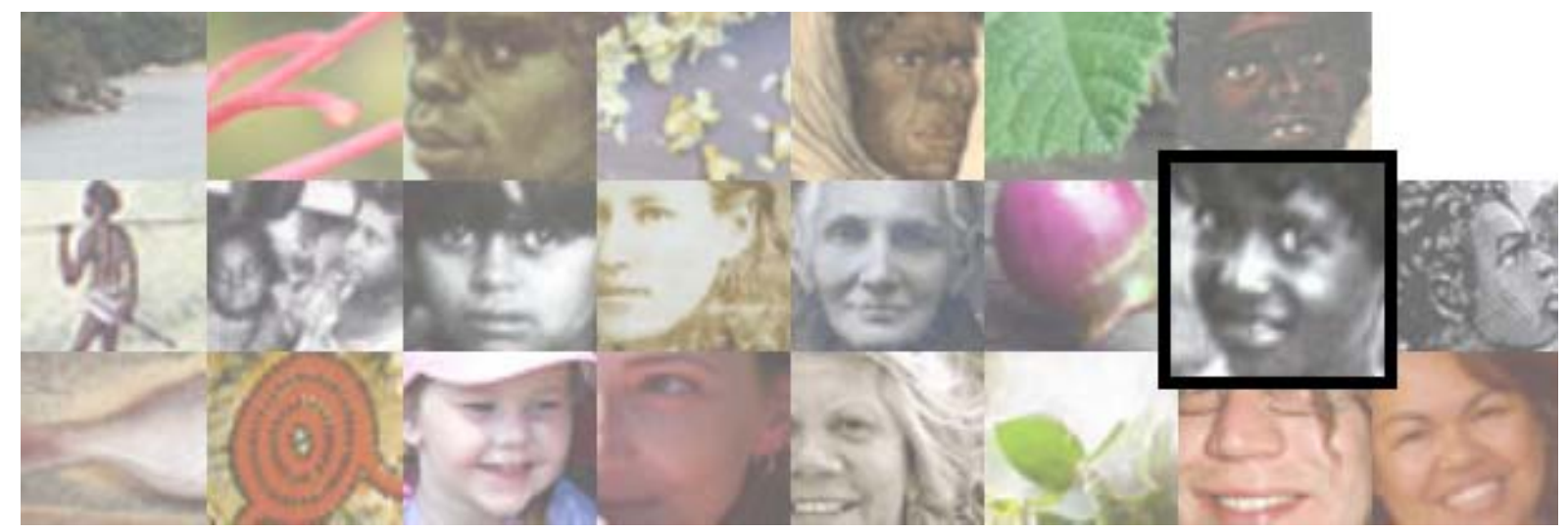

Figure 8. Photographic glimpses

Snippets of photographs in the mosaic (Figure 8) are arranged to tease - to provide opportunities to the observant user to notice some alignments across three time layers and to wonder about inconsistent vertical connections, or to ponder for a moment what is behind a small window into a hidden world. This technique of arranging pictures on websites is not new, but it lends new possibilities and meanings to historical discovery. Subjectivity which may have disappeared from archival exhibits behind the glass is recovered through a moment of wonder, rush of the mind to imagine the hidden and a subjective interpretation of what is revealed - always unfinished, always opening up a space for the imagined. In Aboriginal history where so much is lost, denied and hidden there may never be the final interpretation.

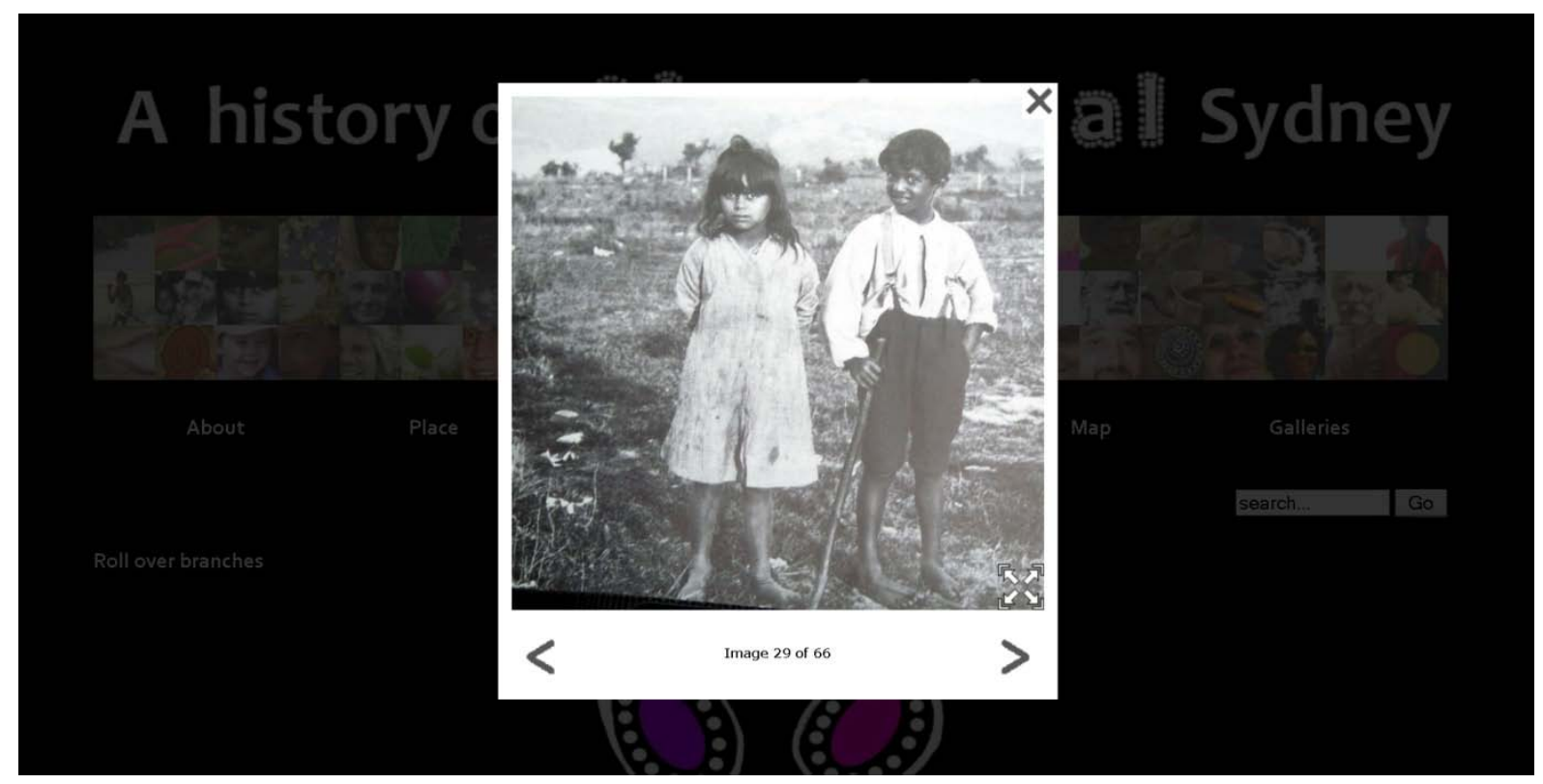

Figure 9. Another intriguing mystery. Who were these children, identified by a visiting Jesuit Priest Father Browne, living at Quaker's Hat Bay, near the Spit, in 1924? 


\section{Educational value}

The essential educational value of the project, we believe, is in discovering Aboriginal presence in the biggest Australian urban centre, which has very little to do with stereotypical images of Indigenous communities in remote areas. Almost all Indigenous students will wish to find out more about themselves and their families. Many non-Indigenous students will come to the website to find information for their assignments and encounter on the first page pictures of people of their own district. While wondering about the continuous Aboriginal presence, some will start discovering Indigenous existence around them and questioning their assumptions. We hope that, while retracing steps either to home or origin, depending on the perspective, some young people will strengthen their understanding of connections between the contemporary urban place and its beginnings.

Our approach to learning and discovery encourages independence, individual sense-making and creative approaches while providing organised space and making sure that students who want specific information can find it as easily as possible.

The significance of spatial information grounds abstract history into locality. Brown (2010) summarised Branting's views on advantages of using geographical information in teaching history and stated that GIS visualises topics, encourages creative approaches to challenging tasks and assists students in developing their own visual displays. Most importantly, it ‘addresses a number of Bloom’s Taxonomy of Higher Levels of Thinking' (cited in Brown, 2010, Introduction). Mostern (2010, Spatial Literacy and History Education, last para.) considered advantages of combining geographical and historical information, and concluded:

From these three insights — that all peoples have a spatial imagination, that geography shapes history, that and space is historical-I conclude that if history students learn to think spatially, they can understand that there are many simultaneous worlds at any time, that multiple histories therefore coexist as well, and that as a result there is no single and linear path of progress.

While learning about Aboriginal history, young visitors to our site will be able to learn about Aboriginal culture, tradition and their environment. The site provides plenty of sources for teachers to develop stimulus material for factual and creative writing. 


\section{Planning an expanding website}

As the space between academic work and presentation for the public is becoming less clear week by week, we develop the knowledge base and consider possibilities for the future. Clearly, we would like to work further on providing secure spaces for teachers and students to engage with our material. An opportunity for a digital space for families to add new information will be essential if the website is to fulfill its potential.

Narrowing also is the space between digital educational presentation and the website as research tool. To increase an understanding of the precisely local, rather than merely 'Sydney', we plan to develop our GPS-based digital map which, already locating and reproducing the entries we cited above, will explore digital 3-D technology. For example, the Sackville Reserve on the Hawkesbury River was established in 1889, reached an apogee in about 1912, and was empty by 1946 (Brook, 1994). Already we have the existing resources of photographs of many of the former inhabitants and one of their homes, some records of the site itself, genealogies, aerial photography and oral histories. To this information we hope to add further interviews, additional aerial photography, Google Earth digital mapping, and heritage information on the construction of Aboriginal owner-builder houses and their precincts. We expect it to be possible to create the Reserve in a three dimensional reconstruction.

At this point the website moves beyond a comprehensive resource base to a significant research tool to enable users to do their own investigations on data such as why official or unofficial reserves were situated where they were, in what relationship did they stand to surrounding clans, work sites, business nodes, schools, trackways, river routes, food resources, ceremonial or social sites and visibility to whites. Who were these people? Where did they come from? Why were they there? Why did they leave? Where did they go? Where are their descendants today? The website should place no limits on where informed and respectful imagination can lead. 


\section{References}

ABS (Australian Bureau Of Statistics ) 2007, 2006 Census QuickStats, ABS, Sydney (Statistical Division).

ABS (Australian Bureau Of Statistics) 2008, 2006 Census Tables, 20680 Number of Persons Usually Resident by Type of Internet Connection by Indigenous Status of Household. ABS, Sydney (Statistical Division),

Ara Irititja Project 2007, Marleston, SA Available: www.irititja.com [Accessed 7 July 2010].

Brook, J. 1994, Shut out from the world : the Sackville Reach Aborigines Reserve and Mission 1889-1946, Seven Hills, N.S.W.

Brown, P. 2010, 'Exploring historical space and environments in the history/social studies classroom: discussion and reflections', Journal of the Association for History and Computing [Online], 13. Available: http://hdl.handle.net/2027/spo.3310410.0013.106 [Accessed 6 July 2010].

Chinn, M. D. \& Fairlie, R. W. 2007, 'The determinants of the global digital divide: a crosscountry analysis of computer and internet penetration', Oxford Economic Papers, 59, $16-44$.

Australian Human Rights Commission 1997, Bringing them home: The 'Stolen Children' report.

Council for Aboriginal Reconsiliation 1991-2000, Council for Aboriginal Reconciliation Archive, University of Technology, Sydney and University of New South Wales Faculties of Law

Goldfarb, A. \& Prince, J. 2008, 'Internet adoption and usage patterns are different: Implications for the digital divide', Information Economics and Policy, vol. 20. pp. 215.

Gunstone, A. 2008, 'Australian Indigenous studies and Australian universities', In: Gunstone, A. (ed.) History, politics \& knowledge : essays in Australian indigenous studies, Australian Scholarly Publishing, Nth. Melbourne, Vic.

Holloway, D. 2005, 'The digital divide in Sydney: a sociospatial analysis', Information, Communication \& Society, vol. 8, pp. 168-193.

Monk, P. \& Tan, F. 2007, Disassembling the archive : Fiona Tan, [Toronto], Art Gallery of York University.

Mostern, R. 2010, 'Putting the world in world history', Journal of the Association for History and Computing. 6 July 2010

Orviska, M. \& Hudson, J. 2009, 'Dividing or uniting Europe? Internet usage in the EU', Information Economics and Policy vol. 21, pp. 279-290.

Porter, C. E. \& Donthu, N. 2006, 'Using the technology acceptance model to explain how attitudes determine Internet usage: The role of perceived access barriers and demographics', Journal of Business Research, vol. 59, pp. 999-1007.

Purcell, T. \& Onjoro, E. A. 2002, 'Indigenous knowledge, power and parity', In: Sillitoe, P., Bicker, A. \& Pottier, J. (eds.) Participating in development : approaches to indigenous knowledge, Routledge, London.

Sydney City Council 2002, Barani: Indigenous history of Sydney city [Online]. Available: http://www.cityofsydney.nsw.gov.au/barani/ [Accessed 6 July 2010].

TKRP 2010, Traditional Knowledge Revival Pathways [Online]. Cairns, Qld. Available: http://tkrp.com.au/index.php?option=com_frontpage\&Itemid=1 [Accessed 6 July 2010].

Willis, S. \& Tranter, B. 2006, Internet diffusion and inequality in Australia. Journal of Sociology, vol. 42, pp. 43-59. 